\title{
Tightening torque and washer size effects on bearing strength of fiber metal laminate bolted-joints
}

\author{
Shiming Zu, Zhengong Zhou, Lu Che, Yanfeng Zhang and Jiazhen Zhang \\ Center for Composite Materials and Structures, Harbin Institute of Technology, 150001, China
}

\begin{abstract}
The study investigated the effect of tightening torque and washer size on the mechanical properties of double-lap, single bolt fiber metal laminate (FML) joints. The tightening torque under the examination was $0.1 \mathrm{Nm}, 3$ $\mathrm{Nm}, 5 \mathrm{Nm}, 10 \mathrm{Nm}$ and $15 \mathrm{Nm}$, and the washer size was changed by varying the value of outer diameter of washer (Dwo $=11 \mathrm{~mm}, D_{w o}=13 \mathrm{~mm}, D_{w o}=15 \mathrm{~mm}, D_{w o}=17 \mathrm{~mm}$ and $D_{w o}=19 \mathrm{~mm}$ ). A three-dimensional (3D) failure finite element model was used to predict the bearing behaviour of FML joints. The comparison between simulation and experimental results showed a good agreement in strength. The results showed that the effect of bolt tightening torque on the failure loads of bolt-loaded FML joints was obvious, and the effect of washer size on the load-bearing capacity was not sensitive. The present work provided supporting information for the design of FML joints.
\end{abstract}

\section{Introduction}

Composite materials have been widely used in aircraft industry due to the high strength and stiffness-to-weight ratios. Fiber metal laminate (FML) is a special kind of composite material which originated at Fokker/TU Delft in the Netherlands[1]. FML is a class of hybrid composites consisting of alternating layers of thin metal sheets and polymer matrix composite. Incorporating composite layers into a metal sheets system greatly enhances the overall performance of the FML which combines the advantages of both conventional composites and metals. In previous studies, FML has been proved to have many excellent mechanical properties such as outstanding fatigue resistance, high specific static properties, superior impact resistance, good residual and blunt notch strength, better bearing strength, fire resistance and corrosion properties [2]. Currently, glass-reinforced aluminium laminate (GLARE) has been selected for the upper fuselage skin structures of Airbus A380, as shown in Figure 1 [3].

Due to advantages in inspection, replacement and reliability, the mechanically fastened joints are of great need in aircraft structures. However, bolted and riveted joints represent potential weak points in a structure due to the highly localized stress, and their efficient design is therefore essential to the load-carrying capacity and the overall weight of the structure[4].

The bearing properties of FML joints have been experimentally researched by scholars [4-9].Wu and Slagter. [5] found that the bearing strength depends on failure mode as influenced by specimen geometry. They concluded that a minimum edge distance-to-diameter ratio (E/D) of 3 and width-to-diameter ratio (W/D) of 4 should be used to develop full bearing strength for pinloaded FML joints. Yeh et al. [8] investigated the bolt type bearing tests on various fiber metal laminates. They found that the bearing strength and the failure mode of FML joints strongly depend on parameters such as the ratio of $\mathrm{E} / \mathrm{D}$, metal volume fraction, and fiber orientation. Frizzell et al. [9] examined the progression of damage from initiation up to ultimate failure in pin-loaded GLARE joints by using microscopy. They also found that GLARE 2 joints displayed significantly higher ultimate bearing strength and strain than GLARE 3 joints.

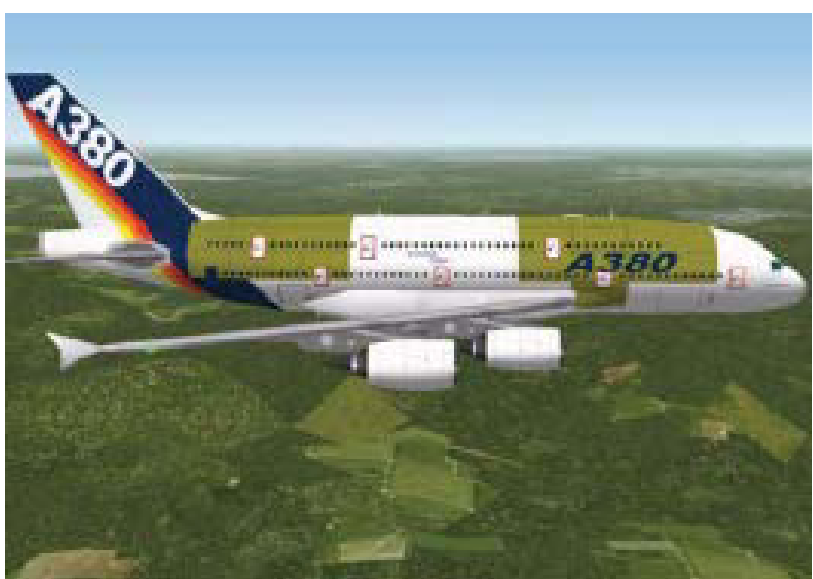

Figure 1. Application of GLARE laminate as the upper fuselage structures for A380 [3].

For complex composite material structure, the use of numerical techniques can be used to get the detailed results efficiently and reduce the number of tests required. Numerical simulation studies of FML joints have been conducted on pin and bolt configurations [7, 10-13]. Van 
Roijen et al. [7] used a finite element model to describe the bearing behaviour of FML joints with varying edge distance radio. It was seen that the model returns a good fit with experimental data for several GLARE laminates. Frizzell et al. [11] investigated the effects of geometry on the mechanical behaviour of pin-loaded FML joints by a numerical study. A continuum damage mechanics model was used to examine the specimens designed to fail in bearing, net-tension and shear-out. The model gave a very good agreement with experimental results for the range of laminate geometries.

In spite of few works focused on the bearing properties of bolt-loaded FML joints, to the best of my knowledge, there is still no published study about the influence of washer size on the bearing properties of the FML joints. This paper aims to investigate the effect of tightening torque and washer size on bearing strength of bolt-loaded FML joints by a three-dimensional (3D) damage model.

\section{Material and methods}

The material used in this study is GLARE 3-3/2-0.4 fiber metal laminate, which includes three layers of $0.4 \mathrm{~mm}$ thick 2024-T3 aluminium alloy and four layers of $0.15 \mathrm{~mm}$ thick HS4 glass fiber/epoxy reinforced prepreg. The resin content in the prepreg was $25.3 \%$ by weight. Mechanical properties of unidirectional HS4 glass fiber/epoxy laminate used in this study are given in Table 1 .

Table 1. Mechanical properties of unidirectional HS4 glass fiber/epoxy laminate.

\begin{tabular}{|l|l|l|}
\hline Symol & Value & Property \\
\hline$E_{11}$ & $54.6 \mathrm{GPa}$ & Longitudinal stiffness \\
\hline$E_{22}$ & $10.5 \mathrm{GPa}$ & Transverse stiffness \\
\hline$E_{33}$ & $10.5 \mathrm{GPa}$ & Out-of-plane stiffness \\
\hline$v_{12}, v_{13}$ & 0.252 & Poisson's ratio \\
\hline$v_{23}$ & 0.32 & Poisson's ratio \\
\hline$G_{12}, G_{13}$ & $3.5 \mathrm{GPa}$ & Shear modulus \\
\hline$G_{23}$ & $3 \mathrm{GPa}$ & Shear modulus \\
\hline$X_{t}$ & $1735 \mathrm{MPa}$ & Longitudinal tensile strength \\
\hline$X_{c}$ & $1037 \mathrm{MPa}$ & $\begin{array}{l}\text { Longitudinal compressive } \\
\text { strength }\end{array}$ \\
\hline$Y_{t}$ & $62.2 \mathrm{MPa}$ & Transverse tensile strength \\
\hline$Y_{c}$ & $144 \mathrm{MPa}$ & $\begin{array}{l}\text { Transverse compressive } \\
\text { strength }\end{array}$ \\
\hline$S_{12}, S_{23}, S_{13}$ & $76.1 \mathrm{MPa}$ & Shear strength \\
\hline$Z_{t}$ & $50 \mathrm{MPa}$ & Out-of-plane tensile strength \\
\hline
\end{tabular}

The FML was cured according to the stacking layup by $[\mathrm{Al} / 0 / 90 / \mathrm{Al} / 90 / 0 / \mathrm{Al}]$ at $120^{\circ} \mathrm{C}$ under the pressure of $0.5 \mathrm{MPa}$ by using vacuum bag/autoclave molding technique. The measured thickness of the cured laminate is $1.8 \mathrm{~mm}$.

The geometry of pin-loaded bearing specimen is shown in Figure 2(a). As shown in this figure, a FML rectangular specimen of length $\mathrm{L}$, width $\mathrm{W}$, thickness $t$ and edge distance $\mathrm{E}$ with a pin hole of diameter $\mathrm{D}$ is considered. Machining techniques should be used in the specimen fabrication. Testing was carried out on an INSTRON-5569 machine in tensile mode. A double shear experimental setup, as shown in Figure 2(b), was used for the pin-loaded bearing test. A $6 \mathrm{~mm}$ diameter steel bolt was inserted into the holes of specimen and pin supports and then loaded under displacement control. The loading speed was $0.5 \mathrm{~mm} / \mathrm{min}$. (a)

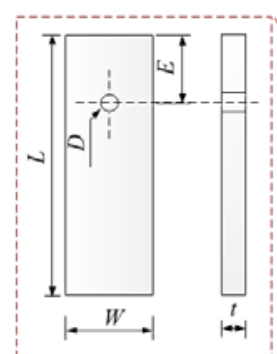

(b)

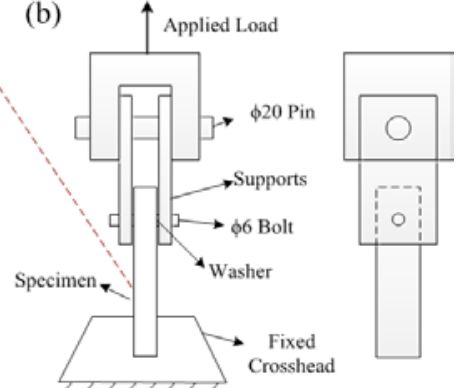

Figure 2. Schematic diagram of (a) specimen, (b) testing setup.

The joint under investigation is a double-lap, single bolt configuration, subjected to a quasi-static tensile load. The specimen geometry is based on the radios of $\mathrm{W} / \mathrm{D}=4$ and $E / D=4$. The outer diameter of washer is $D_{\text {wo }}=13 \mathrm{~mm}$. The tightening torque under the examination is $0.1 \mathrm{Nm}, 3$ $\mathrm{Nm}, 5 \mathrm{Nm}, 10 \mathrm{Nm}$ and $15 \mathrm{Nm}$. A 3D damage finite element model was used to investigate the effect of washer size $\left(D_{\mathrm{wo}}=11 \mathrm{~mm}, \mathrm{D}_{\mathrm{wo}}=13 \mathrm{~mm}, \mathrm{D}_{\mathrm{wo}}=15 \mathrm{~mm}\right.$, $D_{w o}=17 \mathrm{~mm}$ and $D_{w o}=19 \mathrm{~mm}$ ) on bearing behaviour of FML joints.

(a)

i.

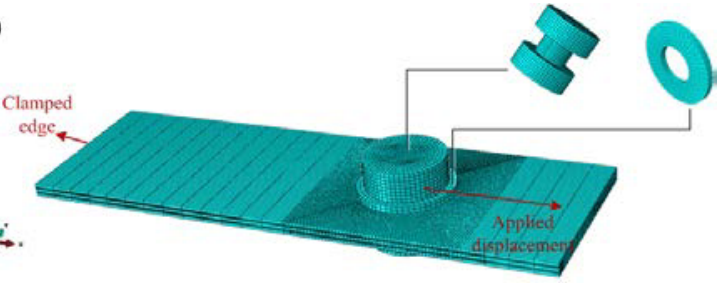

(b)

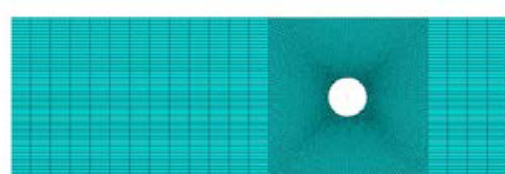

Figure 3. Finite element model of bolt-loaded FML joint.

\section{Finite element model}

In order to reveal the progressive damage process of fiber reinforced polymer layer in FML, a 3D damage model 
based on the Hashin failure criteria has been conducted by using the explicit finite element calculation software ABAQUS/Explicit.

The boundary and loading conditions of the onequarter model are shown in Figure 3. All degrees of freedom were set to zero at the fully clamped laminate end. In order to simulate the realistic loading conditions, an incremental displacement load was applied to the pin in the positive direction. In order to reduce solution runtime, the elements were refined in the vicinity of the pin-hole and reduced further from the hole, as shown in Figure 3(b).

The bolt and washer was meshed using 8-node linear brick, reduced-integration element (C3D8R). The properties of bolt and washer were $E=210 \mathrm{GPa}$ and $v=0.3$. The pre-tightening force of bolt was achieved by changing the temperature of washer. The expansion of washer was $1.35 \times 10^{-5} /{ }^{\circ} \mathrm{C}$. A friction coefficient of 0.1 between bolt and FML was chosen as recommended by Frizzell et al. [11]. The aluminum was meshed using 8node linear brick, reduced-integration elements (C3D8R). The properties of bolt were $E=70.42 \mathrm{GPa}$ and $v=0.33$. The fiber-reinforced epoxy layer, of $0.15 \mathrm{~mm}$ thickness, was meshed using 8-node linear brick, reduced-integration element (C3D8R).

\section{Results and discussions}

The comparison between simulation and experimental load-displacement curves are presented in Figure 4. The specimen geometry was based on the ratios of $W / D=4$ and $E / D=4$. The outer diameter of washer is $D_{w o}=13 \mathrm{~mm}$ and the bolt tightening torque was $5 \mathrm{Nm}$. A good agreement between numerical prediction and experimental data could be found. The failure load of joint simulated by the finite element model is $11061 \mathrm{~N}$. Compared with the average failure load of experimental results, $11450 \mathrm{~N}$, the error of simulation result is only about $-3.4 \%$.

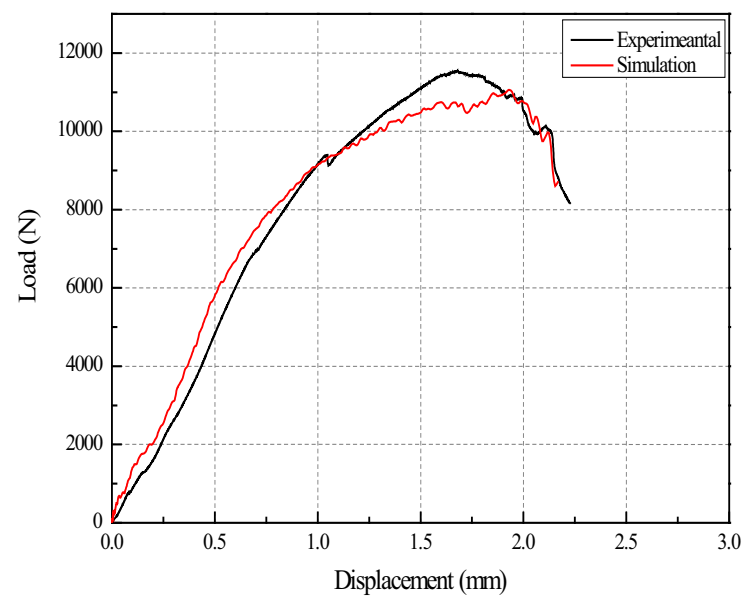

Figure 4. Load-displacement curves of simulation and experimental result $(\mathrm{T}=5 \mathrm{Nm})$.

The internal fiber failure prediction for bolt-loaded FML joints under the $5 \mathrm{Nm}$ torque is shown in Figure 5. It can be seen that the internal fiber failure was localized the bearing plane, which mainly included the $0^{\circ}$ fiber failure, $90^{\circ}$ fiber failure, $0^{\circ}$ matrix failure and $90^{\circ}$ matrix failure. The deformation of the FML joint was localized very near the hole edge, and bearing failure occurred.

\subsection{Effect of tightening torque}

The effect of tightening torque on the bearing behaviour of double-lap, single bolt FML joints was examined by varying the tightening torque force $(T=0.1 \mathrm{Nm}, T=3 \mathrm{Nm}$, $\mathrm{T}=5 \mathrm{Nm}, \mathrm{T}=10 \mathrm{Nm}$ and $\mathrm{T}=15 \mathrm{Nm}$ ). The comparison between simulation and experimental ultimate failure loads are presented in Figure 6.

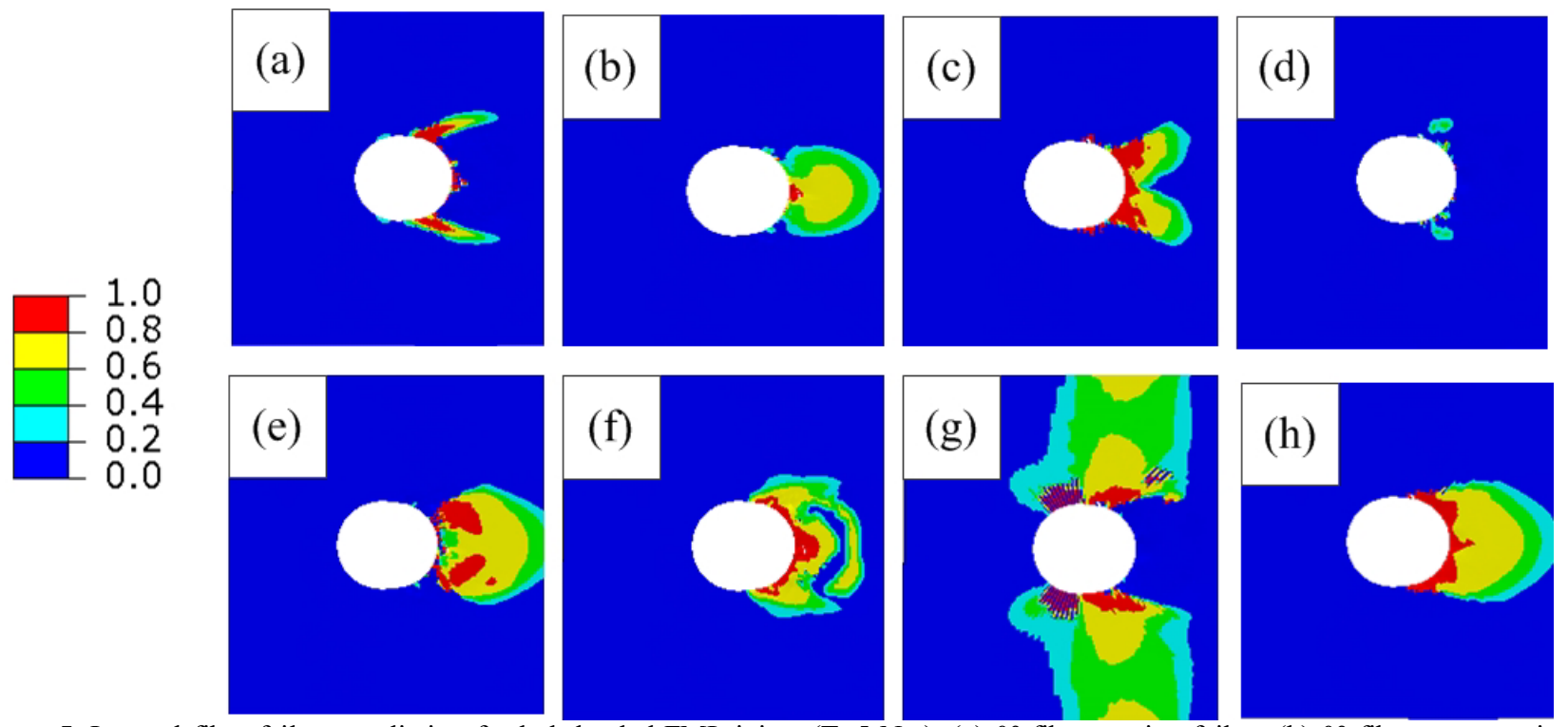

Figure 5. Internal fiber failure prediction for bolt-loaded FML joints $(\mathrm{T}=5 \mathrm{Nm})$, (a) $0^{\circ}$ fiber tension failure,(b) $0^{\circ}$ fiber compressive failure, (c) $90^{\circ}$ fiber tension failure, (d) $90^{\circ}$ fiber compressive failure, (e) $0^{\circ}$ matrix tension failure, (f) $0^{\circ}$ matrix tension failure, (g) $0^{\circ}$ matrix compressive failure, (h) $90^{\circ}$ matrix compressive failure. 
It can be seen that the 3D damage finite element model give a very good agreement with experimental results for the range of bolt tightening torque. The ultimate failure loads of the FML joints increase observably with the increasing values of bolt tightening torque from $0.1 \mathrm{Nm}$ to $10 \mathrm{Nm}$. The increase of ultimate failure loads is not directly when the values of bolt tightening torque increase from $10 \mathrm{Nm}$ to $15 \mathrm{Nm}$. The maximum increase in failure loads occurs on $\mathrm{T}=15 \mathrm{Nm}$ with the rate $20 \%$, in comparison with the results of $\mathrm{T}=0.1 \mathrm{Nm}$. The effect of bolt tightening torque on the failure loads of bolt-loaded FML joints was obvious. Appropriate adding pre tightening force is the effective measures to increase the load-bearing capacity of doublelap, single bolt FML joints.

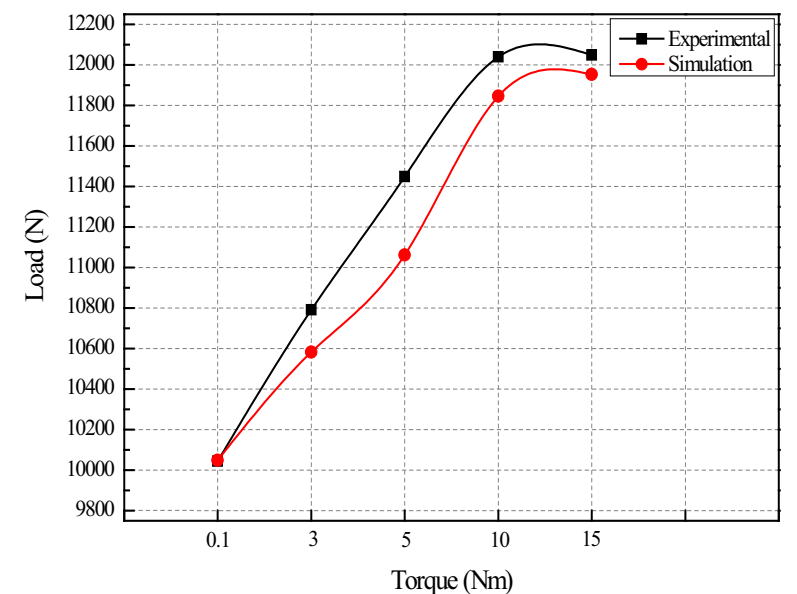

Figure 6. Ultimate failure load of simulation and experimental results.

\subsection{Effect of washer size}

Due to the 3D damage finite element model showed a good agreement with experimental results, the effect of washer size on the bearing behaviour of FML joints was studied by numerical technique. The change of washer size was achieved by changing the outer diameter of washer $\quad\left(D_{\mathrm{wo}}=11 \mathrm{~mm}, \quad D_{\mathrm{wo}}=13 \mathrm{~mm}, \quad D_{\mathrm{wo}}=15 \mathrm{~mm}\right.$, $D_{\mathrm{wo}}=17 \mathrm{~mm}$ and $\mathrm{D}_{\mathrm{wo}}=19 \mathrm{~mm}$ ). Figure 7 shows the comparison between simulation and experimental ultimate failure loads of FML joints under the $\mathrm{T}=0 \mathrm{Nm}$ and $\mathrm{T}=10 \mathrm{Nm}$.

It can be seen that the ultimate failure load of FML joints increase to the maximum and then decrease with the increasing the outer diameter of washer. The Figure 7(a) shows that the maximum increase in failure loads of FML joints $(T=0 \mathrm{Nm})$ occurs on $\mathrm{D}_{\mathrm{wo}}=15 \mathrm{~mm}$ with the rate of $2.5 \%$ in comparison with the results of $D_{w o}=11 \mathrm{~mm}$. When the bolt tightening torque force is $\mathrm{T}=10 \mathrm{Nm}$, the maximum increase in failure loads occurs on $\mathrm{D}_{\mathrm{wo}}=17 \mathrm{~mm}$ with the rate of $2.6 \%$ in comparison with the results of $\mathrm{D}_{\mathrm{wo}}=11 \mathrm{~mm}$. Due to the ultimate failure loads changed little, it can be concluded that the washer size is not sensitive to the bearing strength of double-lap, single bolt FML joints.
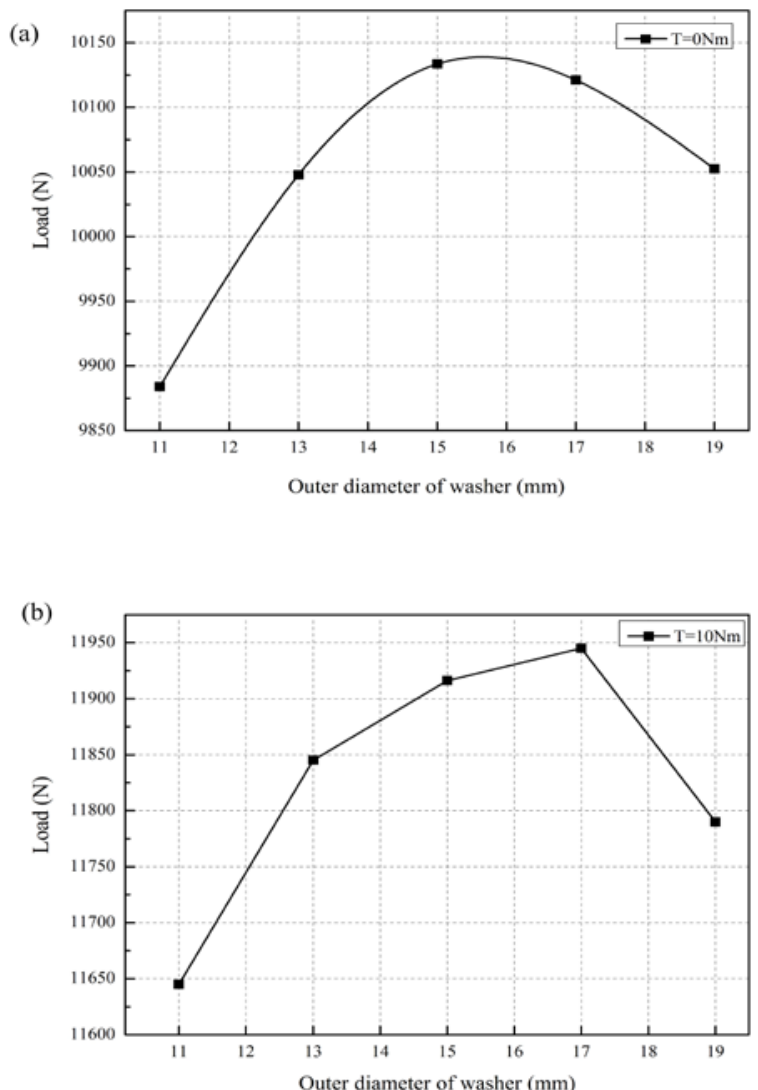

Figure 7. Ultimate failure load of simulation and experimental results (a) $\mathrm{T}=0 \mathrm{Nm}$, (b) $\mathrm{T}=10 \mathrm{Nm}$.

\section{Conclusions}

The present work has investigated the effect of temperature and geometry parameters on the mechanical properties of pin-loaded FML joints. A 3D failure finite element model was used to predict the mechanical behaviour of double-lap, single bolt FML joints with varying the bolt tightening torque force and outer diameter of washer. From the results of this study, the conclusions can be drawn as follows:

(1) The 3D damage finite element model had a good agreement with the experimental results.

(2) The effect of bolt tightening torque on the failure loads of bolt-loaded FML joints was obvious. The ultimate failure loads of the FML joints increase observably with the increasing values of bolt tightening torque from $0.1 \mathrm{Nm}$ to $10 \mathrm{Nm}$. The increase of ultimate failure loads was not directly when the values of bolt tightening torque increasing from $10 \mathrm{Nm}$ to $15 \mathrm{Nm}$. The maximum increase in failure loads occurs on $\mathrm{T}=15 \mathrm{Nm}$ with the rate $20 \%$, in comparison with the results of $\mathrm{T}=0.1 \mathrm{Nm}$.

(3) The effect of washer size on the failure loads of bolt-loaded FML joints was not sensitive. The ultimate failure load of FML joints increased to the maximum and then decreased with the increasing the outer diameter of washer. The maximum increase in failure loads of FML joints with the bolt tightening torque force $(\mathrm{T}=0 \mathrm{Nm}$ and $\mathrm{T}=10 \mathrm{Nm}$ ) was only $2.5 \%$ and $2.6 \%$. 


\section{Acknowledgements}

The present research is supported by the National Science Foundation of China under grand Nos. 11272105, 11572101 and 51271067.

\section{References}

1. A. Vlot, J. W. Gunnink, Fibre metal laminates: an introduction (Springer, 2001).

2. G. Wu, J. Yang, JOM-US, 57, 72 (2005).

3. A. Vlot, History of the development of a new aircraft material (Springer, 2001).

4. R. M. Frizzell C. T. McCarthy, M. A. McCarthy, Composites Part B: Engineering 39, 907 (2008).

5. H. F. Wu, W. J. Slagter, J. Aircraft. 31, 936 (1994).
6. G. Caprino, A. Squillace, G. Giorleo, L. Nele, L. Rossi, Composites Part A: Applied Science and Manufacturing 36, 1307 (2005).

7. R. Van Rooijen, J. Sinke, T. J. De Vries, S. Van Der Zwaag, J. Compos. Mater. 40, 5 (2006).

8. P. Yeh, P. Chang, J. Wang, J. Yang, P. H. Wu, M. C. Liu, Compos. Struct. 94, 3160 (2012).

9. R. M. Frizzell, C. T. McCarthy, M. A. McCarthy, Compos. Sci. Technol. 68, 3314 (2008).

10. P. P. Krimbalis, C. Poon, Z. Fawaz, K. Behdinan, J. Compos. Mater. 41, 1137 (2007).

11. R. M. Frizzell, C. T. McCarthy, M. A. McCarthy, Compos. Struct. 93, 1877 (2011).

12. R. M. Frizzell, C. T. McCarthy, M. A. McCarthy, Compos. Sci. Technol. 71, 1225 (2011).

13. G. Kolks, K. I. Tserpes, Composites Part A: Applied Science and Manufacturing. 56, 51 (2014). 